\title{
Application of GIS and Remote Sensing for Hydropower Development in Nepal
}

\author{
Mahesh Pathak
}

\begin{abstract}
Nepal is endowed with abundant water resources from the availability point of view. Hydropower is considered as a viable means of economic growth for the country's overall development. The river and physiographic characteristics of Nepal offer immense possibilities for the development of hydropower schemes of different scales, and various national and international agencies have expressed keen interest. On the other hand, Nepal's biodiversity resources, a fragile landscape, scattered settlement patterns and natural resource based rural livelihoods are directly affected by hydropower development. Use of recent information about place, people and scientific analysis is crucial for addressing the environmental and socio-economic impacts of development activities. Geographic Information System (GIS) and Remote Sensing (RS) technology have the capabilities to create, update and manage recent information about the earth's surface and its integration with socio- economic information; but these technologies have not been used properly for the hydropower development sector in Nepal. This paper is about the application of GIS and Remote sensing technology to make the hydropower development environment friendly and to create less impact upon the rural livelihood.
\end{abstract}

Key words: GIS, Remote Sensing, hydropower, watershed management, Nepal

\section{The issue}

Tydropower development is the urgent need 1 of the country to mitigate the current power and energy crisis. After political stability, economic development will be the main agenda and hydropower development is the only catalyst for all round development and economic growth of the country. Because of the increasing demand of electricity in Nepal and neighboring country, different national and international agencies are very interested in hydropower development in Nepal. Debate is ongoing whether to promote micro and mini hydropower or to emphasize for mega projects. On the other hand, the geographic characteristics of Nepal have the great potential for hydropower. Being rich in biodiversity, the great challenge for hydropower development in Nepal is to deal with the impacts upon a fragile landscape, biodiversity resources and livelihoods of local communities. There are policies, laws and guidelines for project level Initial Environment Examination (IEE) and Environmental Impact Assessment (EIA) with a view to make development projects environment- friendly. There is, however, a lack of real time information about the people and places. This makes the application of IEE, EIA, feasibility study and project design more time consuming, costly and far from the ground reality. To make hydropower projects environment friendly and to create less impact upon local communities, it is necessary to incorporate Geographic Information System and Remote Sensing technologies into the hydropower sector to analyze natural resources, physiographic characteristics and socio-economic indicators.

\section{Introduction to GIS and Remote Sensing}

Geographic Information Service (GIS) is a computer based information system used to digitally represent and analyze the geographic features present on the earth's surface and the events that are taking place on it. Similarly, Remote Sensing (RS) is the science and art of acquiring information about material objects, area or phenomenon without coming into physical contact with the objects, area or phenomenon under investigation. The integrated approach of GIS and RS is being recognized universally as a unique, highly effective and extremely versatile technology for evaluation, management and monitoring of natural resources and environment. Hydropower development needs integrated approaches to analyzing natural resources, physiographic setting and the socio-economic indicators. GIS plays an important role in every stage of planning, development and implementation. Similarly, timely updated information about landscapes and water resources is the key component for hydropower development. In conventional project handling systems, geospatial data are poorly maintained, maps and statistics are not updated, accurate data and information may not available, data retrieval and data sharing are not easy and, sometimes, available data are not compatible for hydropower. In the GIS environment, geospatial data are better maintained in a standard format, whereby 
the revision, updating, search, analysis and representation of information are easier; hence, both time and money are saved.

\section{GIS and RS for hydropower development in Nepal}

Though Nepal has great potentialities for hydropower, there are lots of things to be considered while designing a hydropower project. Because of geographic setting, there is variation in terms of natural and socioeconomic settings from north to south and east to west. We can find elevation variation from 65 to $8848 \mathrm{~m}$ amsl within very narrow horizontal span from southern plain area to northern Himalayan range. Nepal has three broad physiographic settings: mountains, hills and lowlands (Terai). Around 6,000 rivers and rivulets flow from north to south connecting natural resources and socio-economic situations of all physiographic zone. These rivers have distinct catchments areas in different physiographic zones. Because of the fragile landscape, geological structures and slope variation from north to south, the rivers of Nepal are known as very active drainage systems. Change in river morphology accelerates landslides and mass movement in hill areas and floods in the Terai region. People are using natural resources to sustain their livelihood without considering environmental harmony. Hill areas have the most potential and the most feasible sites for hydropower development, while more than $50 \%$ of total population lives in the downward side; i.e., in the Terai region. Impacts upon the downstream side easily spread towards the Terai lowlands.

Hydropower development in a rugged terrain of Nepal therefore requires the thorough study of geology, topography, land use patterns, distribution patterns of biodiversity resources, infrastructure, socio-economic activities, and so on. Understanding the vast altitudinal variations requires three dimensional (3D) visualization. Because of the geographic settings, carrying out an inventory, feasibility study and baseline survey for hydropower is very difficult, time consuming and costly. But with the help of satellite imageries, acquiring recent and accurate information about topography, land use pattern, river morphology, geology is easier than the conventional way of field survey. Using GIS, we can manage all variables with reference to location, and can provide a clear picture about the hydropower project area and its impact zone. The broad application of GIS and RS technology for digital mapping, river morphology studies, terrain analysis, the integration of socio-economic variables and for modeling and simulation have crucial roles for hydropower development in Nepal.

\section{Digital mapping}

Maps are essential components for hydropower development. Topographic maps of 1:25000 scales are the most frequently used base maps in Nepal. For larger catchment areas, it is difficult to handle several sheets of paper maps. With GIS, we can prepare the digital layers of topographic maps and can handle multiple sheets in a single view. This offers immense potential for interpretation and scientific analysis. Digital layers are very useful for overlay analysis.

We can analyze different layers independently or associated with multiple layers. We can perform query functions and get quick views of our area of interest. Digital layers are easier to edit and update than paper maps. If we conduct a survey of the project area by collecting GPS data we can easily plot them in digital layers. Digital maps will be very useful to prepare project area map quickly and accurately. See Figure 1.

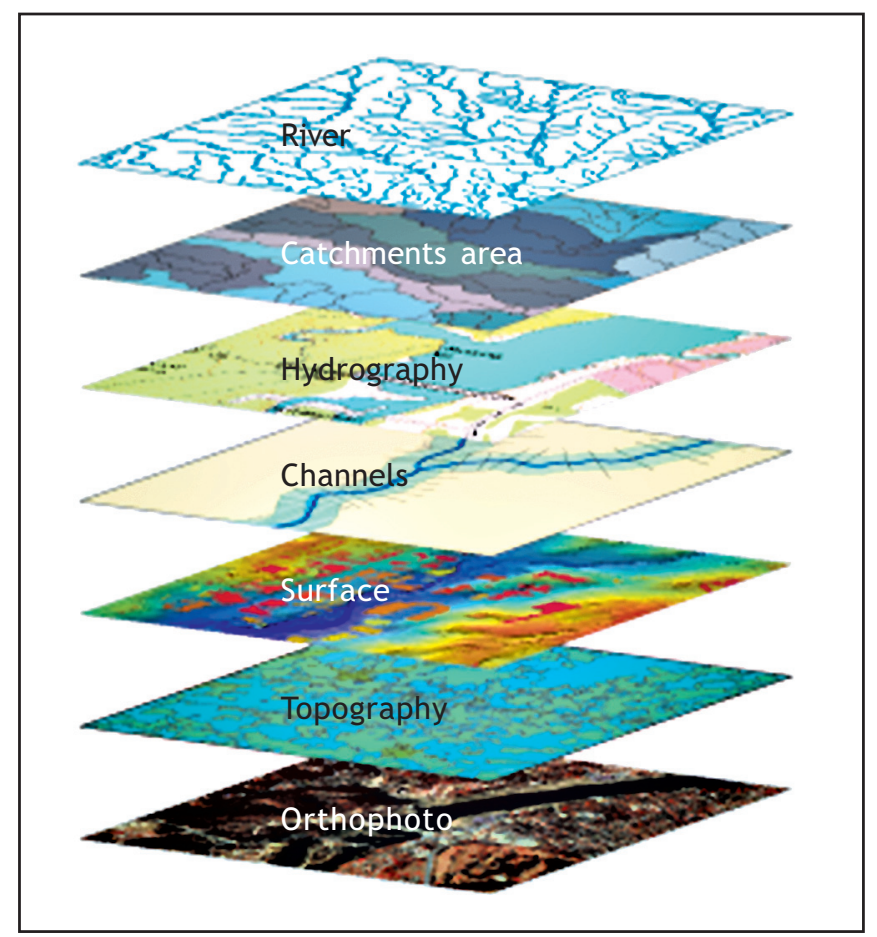

Figure 1. Layer Management in a GIS Database

\section{Drainage database system}

About 6,000 rivers originate from different physiographic region in Nepal. These rivers are part of an active river system and change their courses frequently. Rivers have their own catchment areas with distinct characteristics. For hydropower development and feasibility studies, detailed information about river morphology and catchment areas is very essential. Using GIS and RS tools we can easily map a river's morphology and changing behaviors. Main rivers and their tributary rivers do 
not have equal discharge. Discharge of a single river also varies in its upstream and downstream portions, so it is necessary to carry out detailed studies about all rivers and their characteristics. Some studies have been carried for large river system, but there is a lack of information regarding small and tributary rivers. For hydropower development in Nepal we need, first of all, detailed information about major rivers, their tributaries and watershed characteristics. Using GIS we can calculate water discharge, drainage density and drainage length and prepare a drainage database system. Using satellite imagery we can update the changes occurring in river morphology. A GIS base drainage database system provides the holistic scenario of a river system, which is not possible even when conducting detail field survey. See Figure 2.

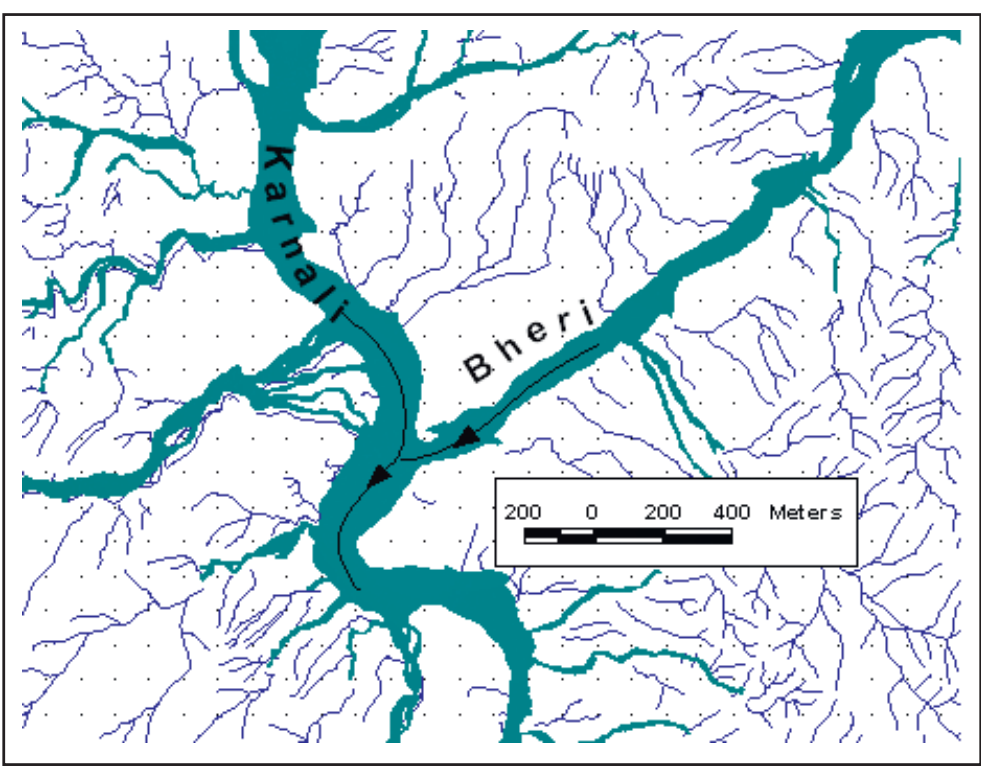

Figure 2. Drainage network map

\section{Terrain analysis}

Because of the altitudinal variation, two dimensional (2D) mapping is not enough to understand the topographic characteristics of Nepal. Three dimensional (3D) mapping is another beauty of GIS and RS technology. It provides a bird eye view of the landscape. With GIS we can create a Digital Elevation Model (DEM), which offers a way to understand the immensely complex topography of hill areas. DEM helps to calculate slope gradient, and north facing and south facing slopes of landscape. These topographic features have significant importance while designing hydropower projects. Using DEM, for example, we can develop different models and simulations to understand various scenarios after constructing a dam in the river channel. Figure 3 .



Figure 3. Drainage network map

Existing 3D values available on 1:25000 scale topographic maps are not enough for hydropower development in hill area of Nepal. While conducting an EIA, feasibility study and project design, detailed field surveys are expensive and time consuming. Due to this, most of the reports lack detailed information regarding the slope variation. This may cause the project failure or cause it to operate at less than full capacity. Using high resolution stereo pair satellite imagery, we can generate contours with less than two meter intervals, which is very useful for understanding the exact topographic settings and to reduce the effort of conducting field surveys.

\section{Watershed mapping}

Hydropower has a multiplier effect as compared to other development activities. Hydropower development impact zones also extend beyond predefined administrative boundary. Therefore, we need a watershed approach to understand the environmental and socio- economic impacts. Landslides, land utilization practices, and forest cover changes have adverse impacts for hydropower. Thus, it is necessary to carry a situational analysis of watershed areas. For example, we have to monitor either landslide events are increasing or being stable and whether the condition of the forest cover is improving or decreasing. These phenomenon play crucial roles for the sustainability of hydropower. Using GIS and RS technology, we can easily delineate the watershed areas. Recent satellite imagery provide recent information about the landscape. With remote sensing techniques we can determine the situation 
regarding landslides and forest area. We can also compare the situation before and after project implementation.

\section{Integration of socio-economic variables}

Socio-economic impact assessment is another challenging issue in hydropower development. To address the socio- economic impacts properly requires integrating socio- economic variables with physical components. Feasibility studies, EIA and project design conducted for hydropower tend to discuss the socio- economic and physical components separately. Integration of socio-economic indicators with physical variables is lacking. GIS has the capability to handle the socio- economic variable with reference to district, VDC or lower level administrative units. We can overlay the socioeconomic information with land use, drainage network, watershed area, and so forth, which is very useful for identifying vulnerable and beneficial communities. Some hydropower projects need to relocate settlements in other suitable areas and pay compensation. Using cadastral maps, we can easily identify the total land required to be compensated. Similarly, GIS analysis also provides potential sites to which project-affected communities can be relocated.

\section{Conclusion}

The topography and geographic setting provides both prospect and problems for hydropower development in Nepal. It requires, therefore, using the most recent and accurate information about place and people, in addition to infrastructure development. GIS and Remote Sensing have emerged as important tools for evaluation, management and monitoring of natural resources and the environment. Using the GIS and RS technology, we can address both the environmental concerns and sociological impacts caused by hydropower development in Nepal.

Mahesh Pathak has expertise in GIS and Remote Sensing applications for land use land cover mapping, river morphology and watershed management. He holds a Masters' Degree in Geography from Tribhhuvan University, for which he was awarded a Gold Medal. He has also received an SCGIS Global Scholarship Award 2007 and took advanced GIS training on conservation and water resource management from ESRI (Environmental Sensitivities Research Institute) in the USA.

Corresponding address: pathakmsh@gmail.com

\section{References}

Agrawal, M.L., B. Maitra and M.K. Ghose, 2005, 'Ecological impact of highway project using GIS', GIS Development GIS Development online at www.gisdevelopment.net/magazine/years/2005/ mar/ecological.htm.

Dudhani, Surekha, A.K. Sinha and S.S. Inamdar, 2006, 'Small hydropower and GIS for sustainable growth in power sector', GIS Development online at www.gisdevelopment.net/proceedings/mapindia/ 2006/energy/mio6ene_166.htm.

Maidment, David R. and Scott Moorhouse, 2002, Arc Hydro: GIS for Water Resources, Redlands, CA (USA): ESRI Press.

Pathak, Mahesh, 2007, 'Application of GIS for conservation and sustainable management of wetland ecosystem in Nepal', a paper prepared for presentation at the 2007 ESRI International User Conference, Monterey, CA, USA, downloadable online at w w w . con s ervationgis.org/ecphistory / Ecp2007Papers.html.

Reddy, M. Anji, 2006, Remote Sensing and Geographical Information System, India: BS Publications.. 